Article

\title{
Application of $\mathrm{Ag} / \mathrm{AgCl}$ Sensor for Chloride Monitoring of Mortar under Dry-Wet Cycles
}

\author{
Yupeng Tian ${ }^{1,2}$, Peng Zhang ${ }^{1,2, * \mathbb{C}}$, Kaiyue Zhao ${ }^{1,2}$, Zhenxing Du ${ }^{3}$ and Tiejun Zhao ${ }^{1,2}$ \\ 1 Center for Durability \& Sustainability Studies, Qingdao University of Technology, Qingdao 266033, China; \\ qdlgtyp@163.com (Y.T.); applezky@126.com (K.Z.); ztjgp@qut.edu.cn (T.Z.) \\ 2 Department of Civil Engineering, Qingdao University of Technology, Qingdao 266033, China \\ 3 School of Materials Science and Engineering, Southeast University, Nanjing 211189, China; \\ 230189193@seu.edu.cn \\ * Correspondence: peng.zhang@qut.edu.cn
}

Received: 2 February 2020; Accepted: 3 March 2020; Published: 4 March 2020

check for updates

\begin{abstract}
An} \mathrm{Ag} / \mathrm{AgCl}$ electrode used as a corrosion sensor in a reinforced concrete structure is considered as having good application prospect. However, its performance under complex conditions, such as dry-wet cycle condition, is not affirmed. In the current study, the performance of $\mathrm{Ag} / \mathrm{AgCl}$ as chloride selective electrode in mortar exposed to dry-wet cycle condition was investigated. A simple $\mathrm{Ag} / \mathrm{AgCl}$ electrode was prepared and fabricated by electrochemical anodization. These $\mathrm{Ag} / \mathrm{AgCl}$ electrodes were embedded into a mortar specimen with temperature sensors, humidity sensors and anode ladder monitoring system (ALS). After $28 \mathrm{~d}$ curing time, the upper surface of mortar specimen was wetted (with $5 \% \mathrm{NaCl}$ solution) and dried regularly. The obtained results indicate that $\mathrm{Ag} / \mathrm{AgCl}$ electrode responds to the ingress of chloride ion, sensitively. The chloride ion concentration variation can be reflected by the potential trend. Furthermore, the balance potential of $\mathrm{Ag} / \mathrm{AgCl}$ electrodes is influenced by dry-wet cycles. Compared with ALS, it demonstrates that $\mathrm{Ag} / \mathrm{AgCl}$ electrodes are more sensitive to chloride. The research provides the key element for the specific application of $\mathrm{Ag} / \mathrm{AgCl}$ electrode for corrosion monitoring in the future.
\end{abstract}

Keywords: reinforced concrete; corrosion monitoring; $\mathrm{Ag} / \mathrm{AgCl}$ electrode; anode ladder monitoring system; dry-wet cycle

\section{Introduction}

Reinforced concrete (RC) has been widely used in coastal environments, such as bridges, docks and offshore platforms, while its unexpected durability always baffles the construction industry [1-3]. Chloride-induced steel corrosion has commonly been accepted as the major reason for deterioration of RC structures [4-6]. In order to continuously monitor steel corrosion, adequate technology with high reliability to reflect chloride ion concentration is a vital element. For determination of distribution and variation of chloride ion in cement-based materials, there are mainly destructive and non-destructive testing methods [6,7]. With regard to non-destructive testing methods, in situ monitoring has the distinct advantage of real-time data acquisition [8-10]. Embedding $\mathrm{Ag} / \mathrm{AgCl}$ electrode into cement-based material as chloride selective electrode (ISE) has a good application prospect. $\mathrm{Ag} / \mathrm{AgCl}$ electrode is highly sensitive to chloride ions [11,12]. The potential response of $\mathrm{Ag} / \mathrm{AgCl}$ electrode is stable in solution with a given chloride concentration. It is reported that the reference electrode prepared by electrolysis had a potential fluctuation of less than $2.7 \mathrm{mV}$ in chloride solution with concentration of $0.1 \mathrm{~mol} / \mathrm{L}$ [13]. In addition, $\mathrm{Ag} / \mathrm{AgCl}$ electrode has the advantages of small temperature coefficient and good reversibility. In general, the common $\mathrm{Ag} / \mathrm{AgCl}$ chloride electrode is a solid-state membrane electrode that consists of an $\mathrm{Ag}$ core with a coating layer of $\mathrm{AgCl}$ [14-18]. For the formation of 
outer $\mathrm{AgCl}$ layer, there are several commonly manufactured methods such as powder pressing, sintering [11,19], chlorination and DC current polarization [20].

With regard to application of $\mathrm{Ag} / \mathrm{AgCl}$, it has been used as the reference electrode for many purposes $[15,20,21]$ and in recent decades has began to be studied in its use as chloride sensor in the concrete industry $[17,22,23]$. Relative attempts to embed $\mathrm{Ag} / \mathrm{AgCl}$ electrodes into cement-based materials were gradually reported since the 1990s [24-27]. After that, many researches have been carried out. Guillem et al. [28] found that chloride ion activity coefficients in concrete inner-pore solutions may be calculated theoretically using Pitzer's model based on the potentiometrically using ISE. Ueli Angst et al. [29] found that $\mathrm{Ag} / \mathrm{AgCl}$ electrodes can be successfully used in highly alkaline environments, and it is only in the complete absence of chloride that the potential is affected by the $\mathrm{pH}$. It is reported the relationship between response potential and the logarithmic functions of ionic activity range from $10^{-4}$ to 2 exhibits well linear [30]. Pargar et al. [31] systematically analyzed the reasons for the difference in working performance of different electrodes. Montemor et al. [32] prepared and studied a multiprobe chloride sensor in solution and also in mortar and concrete samples. Jin et al. [33] revealed that real-time monitoring of free $\mathrm{Cl}^{-}$concentration in concrete was achieved based on the measurements of potentials of embedded electrodes and the diffusion law of free $\mathrm{Cl}^{-}$content followed Fick's second law.

Despite the results in these thoroughly elaborated works, the properties and performance of $\mathrm{Ag} / \mathrm{AgCl}$ electrodes in the alkaline medium are yet to be affirmed, especially in view of their application as chloride sensors for RC structures. For RC structures, chloride often penetrates into their interior from the outside environment, which is a chloride uptake process. When concrete is exposed to the hydrostatic pressure, water penetrates into concrete by capillary suction. Although the water front and chloride penetration front are different due to the filtration effect [34], the penetration depth of water determines the penetration depth of chloride ions. As is known, most outdoor RC is inevitably subjected to dry-wet cycle condition $[35,36]$. The improvement of chloride ions permeation caused by dry-wet cycle leads to concrete facing higher risk of chloride-induced deterioration [37]. Accordingly, it is of importance to study the performance of $\mathrm{Ag} / \mathrm{AgCl}$ electrode under dry-wet cycle condition.

The objective of the present investigation is to evaluate the performance of $\mathrm{Ag} / \mathrm{AgCl}$, as chloride ion sensor, for in situ monitoring of cement-based material under dry-wet cycle condition. As an extension of previous research [38], in this paper, $\mathrm{Ag} / \mathrm{AgCl}$ electrodes as working electrode and $\mathrm{MnO}_{2}$ as reference electrode were first prepared. Reliability of $\mathrm{Ag} / \mathrm{AgCl}$ electrode was tested by calibration. $\mathrm{Ag} / \mathrm{AgCl}$ electrode system, anode ladder monitoring system (ALS), temperature sensor and humidity sensor were embedded in mortar sample. Dry-wet cyclic test was implemented by regular surface impregnation to accelerate the ingress of chloride into a sample. The performance of $\mathrm{Ag} / \mathrm{AgCl}$ with chloride ingress will be present and discussed. By the results presented in this investigation, the efficiency of $\mathrm{Ag} / \mathrm{AgCl}$ electrode application in practical cement-based material is evaluated.

\section{Experimental Materials, Methods and Technical Background}

\subsection{Materials and Sample}

Mortar cube specimen with dimensions of 170 (height) $\mathrm{mm} \times 600$ (width) $\mathrm{mm} \times 900 \mathrm{~mm}$ (length) was manufactured using a water to cement ratio of 0.55 . The amounts of cement, sand and water used per cubic meter were 515, 1350 and $283 \mathrm{~kg}$, respectively. The cement used was Ordinary Portland Cement with 42.5 degrees. The natural river sand used was from Qingdao area, with a maximum diameter of less than $5 \mathrm{~mm}$. No superplasticizer admixtures were added during the casting process. After demoulding, the tested specimen was placed in stable humidity and temperature condition at around $20 \pm 3^{\circ} \mathrm{C}$ and $60 \% \mathrm{RH}$. For the first 14 days of a total 28 days curing time, the specimen was cured by continuous pouring water. Then it was dried for 14 days to promote ingress of $\mathrm{Cl}^{-}$into the specimen. 


\subsection{Preparation and Installation of Sensors}

\subsection{1. $\mathrm{Ag} / \mathrm{AgCl}$ Electrode}

It is reported that a current density above $2 \mathrm{~mA} / \mathrm{cm}^{2}$ may lead to $\mathrm{AgCl}$ layer heterogeneity and ionic resistivity [11]. In this paper, $\mathrm{Ag} / \mathrm{AgCl}$ probes were fabricated by applying $0.5 \mathrm{~mA} / \mathrm{cm}^{2}$ direct current (DC) on sterling silver (9.9 purity) with $2.5 \mathrm{~mm}$ diameters and $20 \mathrm{~mm}$ long for $2.5 \mathrm{~h}$ polarizations. Before DC polarization, raw Ag bar was pretreated as follows: $20 \mathrm{~mm}$ long Ag bars were zoned as 5 and $15 \mathrm{~mm}$. The $5 \mathrm{~mm}$ end was used to connect copper conductor by welding. The welding zone was sealed with epoxy to prevent copper wire and Ag bar from electric couple corrosion. The $15 \mathrm{~mm}$ end to be polarized was polished with sandpaper (NO 1000) and was rinsed with acetone to remove residue and grease. Surface of Ag bar is vulnerable to be oxidized during polished process. In order to move the outer oxide layer, Ag bar was therefore immersed in 5\% nitric acid solution for $60 \mathrm{~s}$; then, Ag bar was orderly rinsed by ethyl alcohol and deionized water.

Considering the outer AgCl layer is vulnerable to being destroyed, a PVC tube with inner diameter of $20 \mathrm{~mm}$ was used to pack the electrode. Front end of prepared electrode $10 \mathrm{~mm}$ long was embedded in a semi-permeable film. This semi-permeable film, longwise, $25 \mathrm{~mm}$ long, is virtually composed of cement-based fillers (cement: sand: water: sawdust $=48: 48: 19.2: 2.5$ ), which is able to protect the electrode and allow the pore solution to penetrate. The remaining $10 \mathrm{~mm}$ long end of prepared electrode was sealed by epoxy resin to fix the $\mathrm{Ag} / \mathrm{AgCl}$ electrode. The schematic diagram of $\mathrm{Ag} / \mathrm{AgCl}$ electrode is presented in Figure 1.

\subsection{2. $\mathrm{MnO}_{2}$ Electrode}

$\mathrm{MnO}_{2}$ electrode has been commonly used as a reference electrode because of its good stability [39]. The composition of $\mathrm{MnO}_{2}$ electrodes used in this study includes manganese powder, manganese dioxide powder, carbon powder and polytetrafluoroethylene, with a ratio of 1:6:2:1. After the raw materials were mixed, the mixture was stirred with high-speed dispersing homogenizer and grinded into powder. $\mathrm{MnO}_{2}$ electrode $(\mathrm{h}=5 \mathrm{~mm}, \mathrm{~d}=10 \mathrm{~mm}$ ) was prepared by direct compression method with 96 Mpa. PVC tube with an inner diameter of $10 \mathrm{~mm}$ was used as the shell of the electrode. Internal fills were subdivided into 4 layers, namely, mortar semi-permeable membrane (10 mm), alkalinegel (5 mm), $\mathrm{MnO}_{2}$ electrode $(5 \mathrm{~mm})$, epoxy resin $(20 \mathrm{~mm})$. The schematic diagram of $\mathrm{MnO}_{2}$ electrode is given in Figure 1. The temperature coefficient is $0.25 \mathrm{mV} /{ }^{\circ} \mathrm{C}$, which shows that the temperature has little effect on the potential of the reference electrode. Some other details can be found in the previous study [38].

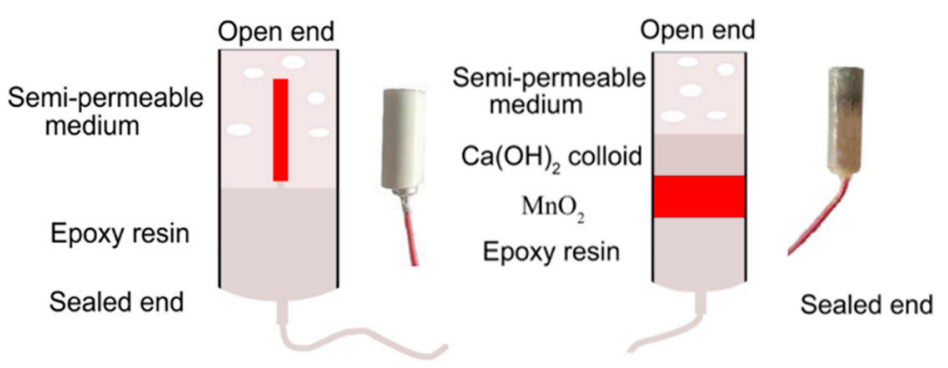

Figure 1. Package schematic diagram of $\mathrm{Ag} / \mathrm{AgCl}$ and $\mathrm{MnO}_{2}$ electrode.

\subsubsection{ALS and Humidity Sensor}

The common ALS consists of six anodes and one cathode as showed in Figure 2. The so-called anodes are comprised by six common carbon steel bars, and the cathode is made of platinum-plated titanium rod. The ALS in this paper is supplied by Shanghai Lrel Instrument Equipment Co. in China. When the ammeter connects the anode carbon steel bars to platinum bar, the corrosion current can be orderly obtained. The corrosion potential of each anode was measured with a voltmeter by connecting the anode carbon steel bars to the platinum bar. Humidity sensors, which are the chip sensor from 
Qingdao Jiaqi Electron Equipment Co. in China, with an accuracy of $2 \%$, helped explain the water penetration process.

\subsubsection{Installation and Position of Sensors}

If the chemical composition of the electrolyte near ISE is different from that around the reference electrode, the diffusion potential will become an error source [27]. To avoid error from diffusion current, which is possibly induced by location difference with $\mathrm{pH}$ between the working electrode and the reference electrode, the $\mathrm{MnO}_{2}$ electrode was positioned as close $\mathrm{Ag} / \mathrm{AgCl}$ probe as possible. In order to simulate the application of the ALS in the real environment, the ALS was mounted on a steel mesh, which was made by HPB300 carbon steel with a diameter of $12 \mathrm{~mm}$. Specific installation location is shown in Figure 2. With regard to installation of humidity sensor, PVC tubes with $15 \mathrm{~mm}$ diameters were fixed to ensure the sensors at the designated location in the specimen. Furthermore, such positioning measures avoid humidity sensor to contact with water, which may result in failure of the chip sensor. After 28 days curing time, the humidity sensor was sealed into the reserved PVC tubes. The detailed location information of sensors from the sample surface is given in Table 1.

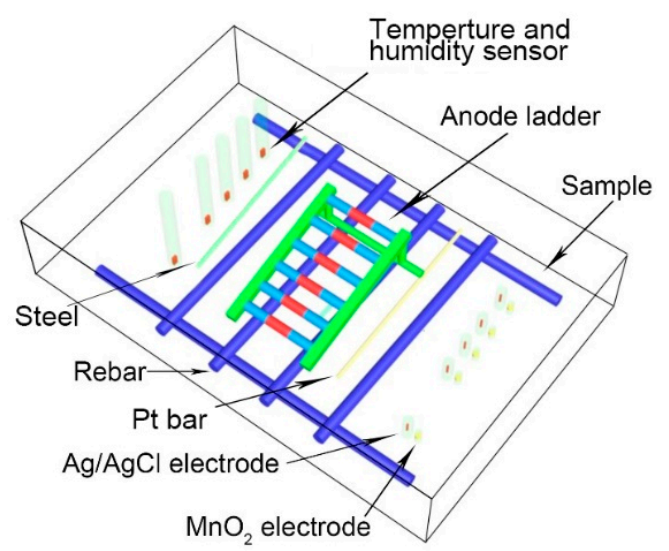

Figure 2. Position of $\mathrm{Ag} / \mathrm{AgCl}$ electrode, $\mathrm{MnO}_{2}$ electrode, anode Ladder monitoring system (ALS), temperature sensor and humidity sensor in mortar sample.

Table 1. Embedded depth of sensors.

\begin{tabular}{cc}
\hline Sensor & Depth \\
\hline H1/C1/T1/A1 & $10 \mathrm{~mm}$ \\
H2/C2/T2/A2 & $25 \mathrm{~mm}$ \\
H3/C3/T3/A3 & $40 \mathrm{~mm}$ \\
H4/C4/T4/A4 & $55 \mathrm{~mm}$ \\
H5/C5/T5/A5 & $85 \mathrm{~mm}$ \\
ALS cathode (carbon steel) & $100 \mathrm{~mm}$ \\
ALS reference electrode of (Pt.) & $55 \mathrm{~mm}$ \\
\hline
\end{tabular}

Notes: $\mathrm{H}$ is the humidity sensor; $\mathrm{C}$ is the $\mathrm{AgCl} / \mathrm{Ag}$ electrode; $\mathrm{T}$ is the temperature sensor; $\mathrm{A}$ is the anode ladder monitoring system.

\subsection{Calibration in Solution}

The synthetic pore solution was obtained by diluting $\mathrm{NaCl}$ into saturated $\mathrm{Ca}(\mathrm{OH})_{2}$ solution. Five types of synthetic pore solution with $1,0.5,0.1,0.01,0.001 \mathrm{M} \mathrm{NaCl}$ were used to calibrate the potential of $\mathrm{Ag} / \mathrm{AgCl}$ sensor. The electrode potentials were tested at a constant temperature of $20 \pm 1{ }^{\circ} \mathrm{C}$. The tested electrode was rinsed after each measurement to avoid residual solution influence response time. 


\subsection{Application of $\mathrm{Ag} / \mathrm{AgCl}$ Electrode in Mortar}

In order to expedite ingress of chloride into sample, dry-wet cyclic condition was conducted by $5 \%$ (by mass) $\mathrm{NaCl}$ solution. During the wetting phase, $\mathrm{NaCl}$ solution was continually poured on the upper surface of the sample to maintain a liquid level $2 \mathrm{~mm}$ high than sample surface height. Correspondingly, drying process was accelerated by an electric fan with wind speed of $3.5 \mathrm{~m} / \mathrm{s}$. In order to obtain a visible corrosion process, different circulation systems have been selected to obtain an appropriate rate of water penetration: for first eight cycles, specimen was wetted for $6 \mathrm{~h}$ and dried for $18 \mathrm{~h}$. Then, the next 8-29 cycles specimen was wetted for $6 \mathrm{~h}$ and dried for $42 \mathrm{~h}$. For last 30 cycles, specimen is wetted for 12 hours and dried for $60 \mathrm{~h}$.

\subsection{Ag/AgCl Electrode Theoretical Background}

The $\mathrm{Ag} / \mathrm{AgCl}$ chloride electrode is one solid-state membrane electrode which usually consists of a silver core with a coating of $\mathrm{AgCl}$. Due to such coating has a low solubility, $\mathrm{AgCl}$ tends to be saturated in the electrolyte. When the overall ionic strength of the aqueous solutions is low, chloride ion activity and concentration are approximately equal. The relationship of the interfacial potential of $\mathrm{AgCl}$ electrode and chloride ion activity can be expressed by Nernst's law [10,37], as Equation (1). The chloride concentration can be obtained by Equation (2).

$$
\begin{gathered}
\mathrm{E}_{\mathrm{Ag} / \mathrm{AgCl}}=\mathrm{E}_{\mathrm{Ag} / \mathrm{AgCl}}^{0}-\frac{\mathrm{RT}}{\mathrm{nF}} \operatorname{In}\left[\alpha_{\mathrm{Cl}-}\right] \\
\alpha_{\mathrm{Cl}-}=\mathrm{e}^{\frac{\mathrm{nF}}{\mathrm{RT}}\left(\mathrm{E}_{\mathrm{Ag} / \mathrm{AgCl}}^{0}-\mathrm{E}_{\mathrm{Ag} / \mathrm{AgCl}}\right)}
\end{gathered}
$$

where, $\mathrm{E}_{\mathrm{Ag} / \mathrm{AgCl}}$ represents the actual measured value, which is the measured open-circuit potential of $\mathrm{AgCl}$ electrode versus a reference electrode. $\mathrm{E}_{\mathrm{Ag} / \mathrm{AgCl}}$ represents standard potential of $\mathrm{Ag}-\mathrm{AgCl}$ equilibrium. $\mathrm{R}$ is the gas constant, which is $8.3144 \mathrm{~J} /(\mathrm{K} \cdot \mathrm{mol})$. T is the absolute temperature $(\mathrm{K})$. F is the Faraday Constant, which is $96.487 \mathrm{KJ} /(\mathrm{V} \cdot \mathrm{mol}) . \mathrm{n}$ is the valence. $\alpha_{\mathrm{Cl}}$ is the activity of the chloride ions in solution. Actually, the calibration curves can be simplified by linear regression analysis according to following Equation (3):

$$
\mathrm{E}_{\mathrm{Ag} / \mathrm{AgCl}}=\mathrm{m} \operatorname{In}\left[\alpha_{\mathrm{Cl}-}\right]+\mathrm{b}
$$

A high concentration of hydroxide ion, such as pore solution of cement-based materials, may induce interference in the potentiometric determination of the chloride concentration with an $\mathrm{Ag} / \mathrm{AgCl}$ electrode [27]. The chloride concentration can be calculated by employing the activity coefficient $\gamma_{\mathrm{Cl}-}$ [28], which can been expressed by Equation (4).

$$
\alpha_{\mathrm{Cl}-}=\mathrm{C}_{\mathrm{Cl}-} \cdot \gamma_{\mathrm{Cl}-}
$$

Many studies have been done to get $\gamma_{\mathrm{Cl}-}[28,40]$. According to literature [40], the $\gamma_{\mathrm{Cl}-}$ was calculated for expressed pore solution and when the chloride concentration from 0.1 to $1.0 \mathrm{M} \gamma_{\mathrm{Cl}}$ value is from 0.656 to 0.604 .

\section{Results and Discussion}

\subsection{Calibration in Solution}

The potentiometric response behaviors of $\mathrm{Ag} / \mathrm{AgCl}$ electrodes with increasing chloride concentration at $20 \pm 2{ }^{\circ} \mathrm{C}$ are exhibited in Figure 3. It is apparent that there is an excellent agreement between potentials of $\mathrm{Ag} / \mathrm{AgCl}$ electrodes and their corresponding linear fitting, with a correlation coefficient of 0.99 . This is a clear indication that the prepared $\mathrm{Ag} / \mathrm{AgCl}$ electrodes have well working performance. The calibration curves can be expressed by the linear regression equation in Equation (2), which is also shown in Figure 3. 


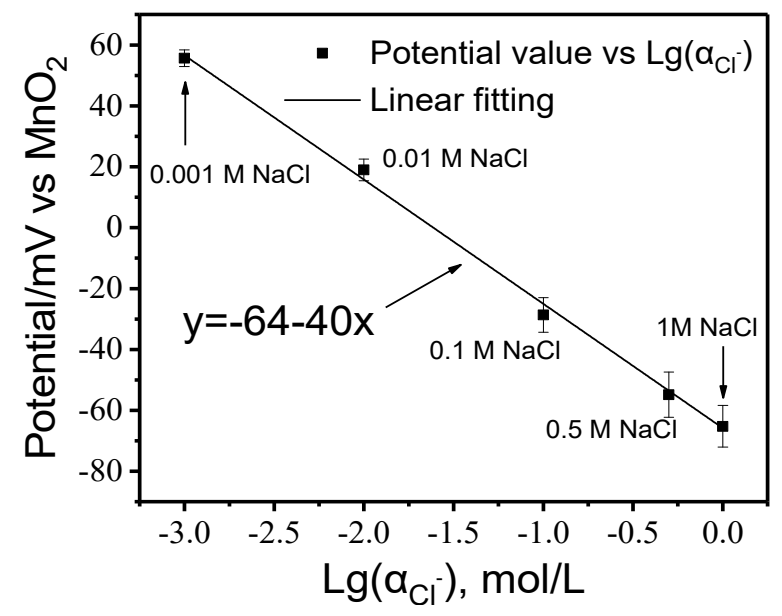

Figure 3. The calibration curve of $\mathrm{Ag} / \mathrm{AgCl}$ in synthetic pore solution.

\subsection{Application of $\mathrm{Ag} / \mathrm{AgCl}$ Electrode in Mortar}

The chloride ions are introduced into the mortar sample using dry-wet cycle by $5 \% \mathrm{NaCl}$ solution. Because water is an effective carrier of chloride ions, the chloride penetration depth can to some extent be reflected by the humidity sensor. The humidity conditions of mortar with the same depth as $\mathrm{Ag} / \mathrm{AgCl}$ electrodes are depicted in Figure 4. It illustrates that water can easily reach $\mathrm{H} 1-\mathrm{H} 3$ humidity sensor, but it is of relative difficulty to reach $\mathrm{H} 4$ and $\mathrm{H} 5$. Potential evolution of $\mathrm{Ag} / \mathrm{AgCl}$ electrode to chloride ion in mortar with dry-wet cycle development is depicted in Figure 5. Although the potential responses of $\mathrm{Ag} / \mathrm{AgCl}$ electrodes to $\mathrm{Cl}^{-}$in synthetic pore solution with various chloride ion concentrations show good linearity, the obtained potential curves in mortar fluctuate remarkedly. The maximum fluctuation range between two adjacent potential values reached Ca. $100 \mathrm{mV}$. In fact, the potential curves obtained by $\mathrm{Ag} / \mathrm{AgCl}$ electrode testing the continuous capillary absorption of chloride solution into concrete are relatively flat; therefore, this indicates that the dry-wet cycle does influence the testing error of $\mathrm{Ag} / \mathrm{AgCl}$ electrode.

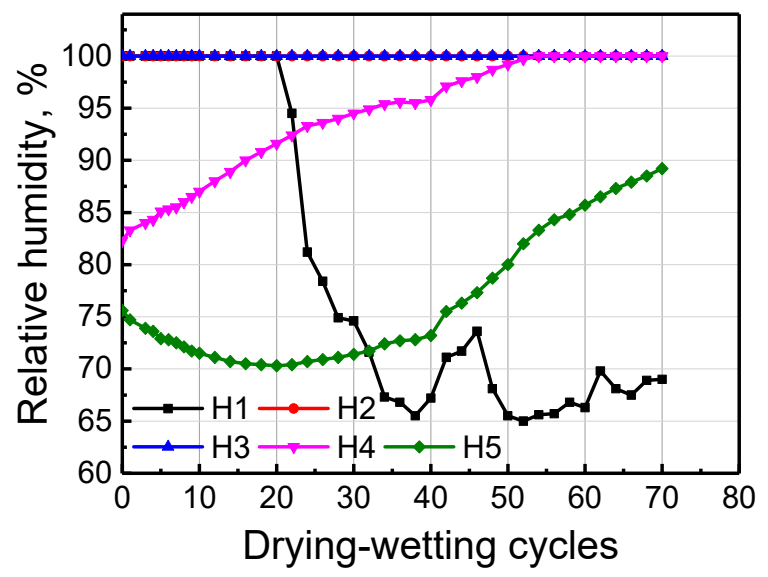

Figure 4. Development of interior relative humidity of mortar with dry-wet cycles.

Furthermore, it is observed that as dry-wet cycle increases from 10 to 70 , potential values exhibit evident overall upward or downward trend. Downward of potential values means increase of chloride concentration and lowering of slope the faster the chloride concentration increases; conversely, the concentration of chloride ions will decrease. The result of Figure 5 illustrates that chloride concentration at installation depth of $\mathrm{C} 1$ and $\mathrm{C} 2$ increases continuously. With regard to C3-C5, the slope of curves tends to increase, and this can be explained by a decrease in the free chloride content caused by physical adsorption and chemical binding of chloride ions by hydration products. 
In addition, because the sample was only cured with sufficient water for 15 days, there existed many unhydrated cement particles. Continuous hydration may lead to the increase of concrete alkalinity. Even for fresh concrete, the $\mathrm{pH}$ value is able to reach to 12.5 [7]. High concentration hydroxide has a certain inhibitory effect on activity of chloride ions, and there is a certain competitive relationship between phase hydroxide and chloride ion [29]. When the concentration of chloride ions is relatively low in highly alkalinity solution, oxidation film will be formed instead of $\mathrm{AgCl}$, leading to a decrease of potential. It is also noticed that during early cyclic period before 15 cycles, the curve fluctuates greatly. This is because AgOH layer might be formed due to low chloride concentration [8]. Silver hydroxide is unstable and tends to convert to argentous oxide and water as expressed in Equation (5) [41]:

$$
\mathrm{AgOH} \rightleftarrows \mathrm{AgO}+\mathrm{H}_{2} \mathrm{O}
$$

Moreover, it is obvious that the potential is relatively stable after 15 cycles, which is due to the sensor being able to recover quickly once it comes into contact with chloride ions [28].

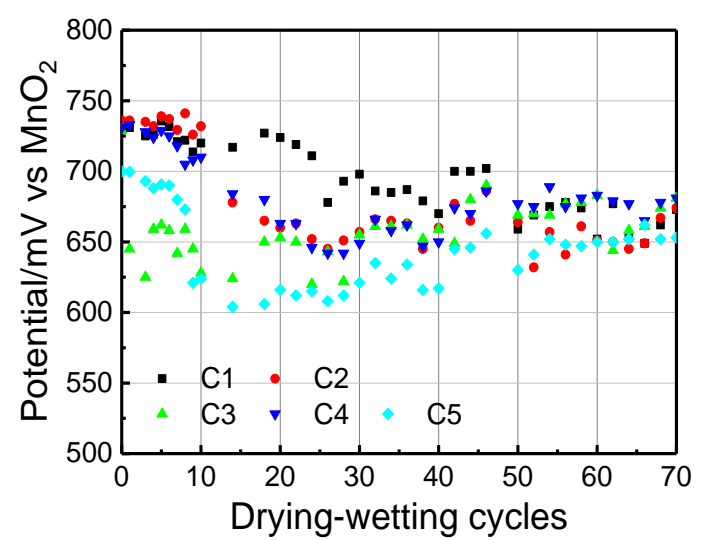

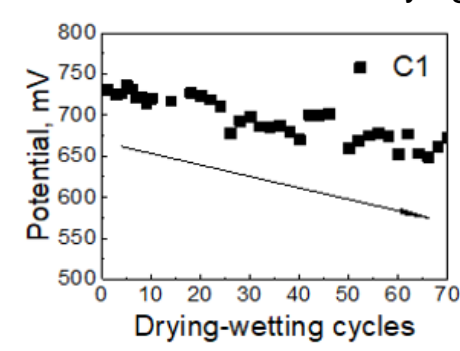

(a)

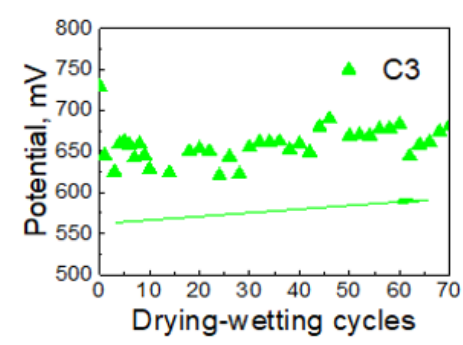

(c)

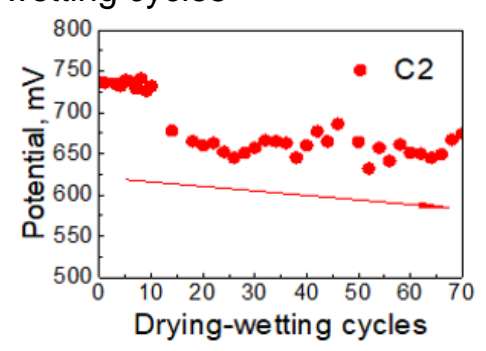

(b)

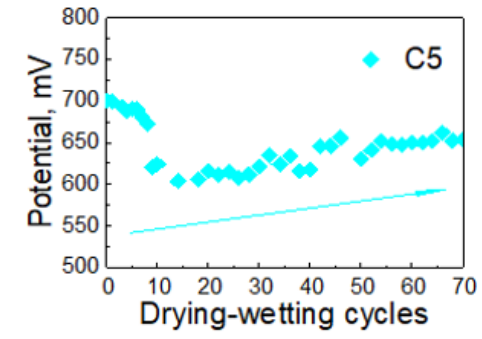

(d)

Figure 5. Potential evolution with the development of dry-wet cycles of $\mathrm{Ag} / \mathrm{AgCl}$ electrodes in mortar sample.

Regarding the results in Figure 5, the chloride concentration can be calculated by the linear function in Figure 3. The activity coefficient $\gamma_{\mathrm{Cl}}$ - was approximately selected as 0.6 according to literature [40]. It can be observed that the chloride concentration displays an increasing trend at the early age but shows a different trend after 15 cycles as shown in Figure 6. The chloride concentration at $\mathrm{C} 1$ depth continued to increase, while that at $\mathrm{C} 2$ depth was relatively stable. However, the concentration 
of chloride ions at relatively deep depths showed a trend of continuous decline. The continuous decrease in $\mathrm{C} 5$ is mainly attributed to the fact that chloride ions cannot enter the mortar sample in large quantity in a short time. Moreover, the original ions gradually decrease due to the physisorption and chemisorption. The main product of chemisorption is the so-called Friedel's salt [32]. In general, the change of chloride concentration should be sensed much earlier by the outer-layer $\mathrm{AgCl}$ electrode, but there is no obvious increase trend of $\mathrm{C} 1$. This phenomenon can be attributed to the heterogeneity of cement mortar or the cracks. In this case, the $\mathrm{AgCl}$ electrode with a deeper depth responds slowly. This also indicates the limitation of $\mathrm{AgCl}$ electrode that it can only detect the concentration of chloride ions in a small domain.

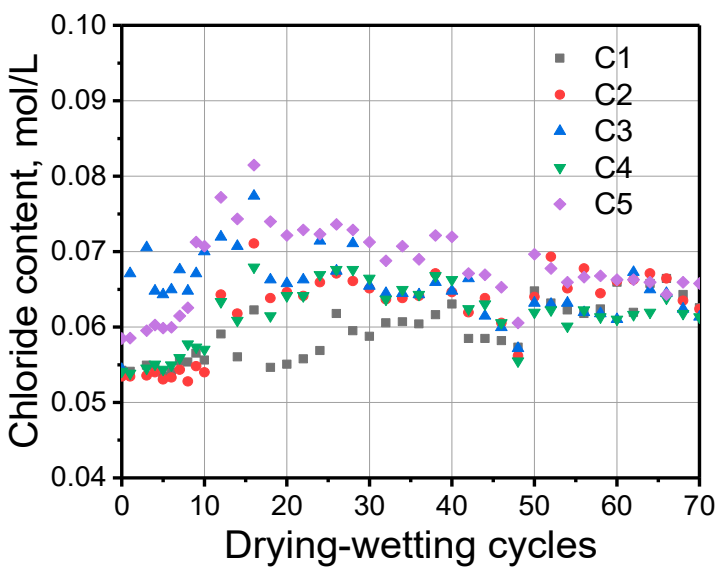

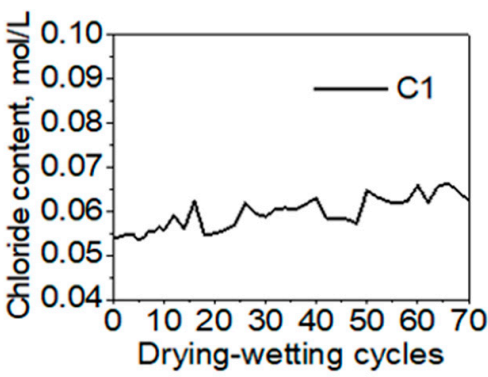

(a)

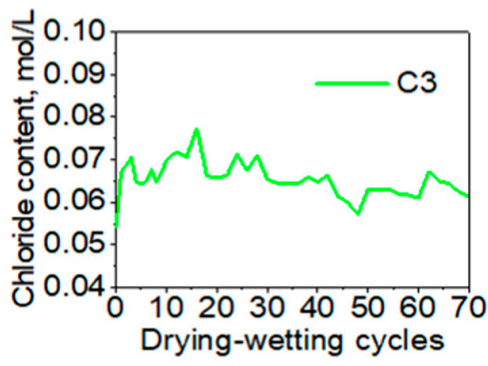

(c)

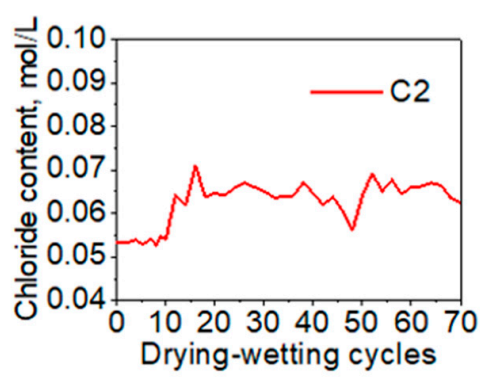

(b)

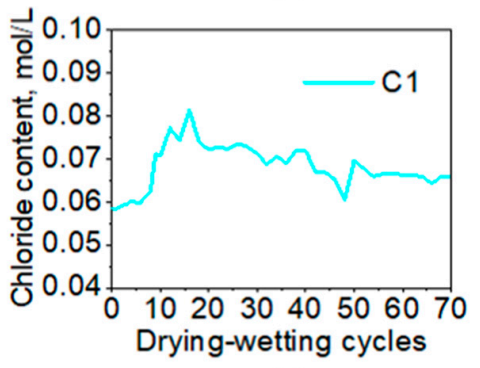

(d)

Figure 6. Chloride concentration calculated by Nernst's law with the absence of temperature correction.

In Figure 7, the temperature of the tested position of each $\mathrm{Ag} / \mathrm{AgCl}$ electrode is obtained by the temperature sensor. The influence of temperature on the $\mathrm{Ag} / \mathrm{AgCl}$ detected result is remarkable according to the Nernst's law. In order to investigate the influence of temperature on potential value, the chloride concentrations in the presence of temperature correction were calculated. The results are shown in Figure 8. After the temperature correction, the data dispersion is relatively smaller. However, the chloride concentration values according to $\mathrm{C} 1-\mathrm{C} 4$ are high at the beginning of the water penetration process. This is because the cracks in the sample provide the water channel as shown in Figure 4. Extracting the data at 20, 40, 60 cycles, Figure 9 can be obtained. It illustrates the distribution of chloride ions related to the depth. It can be seen that the concentration of chloride is obviously lower 
at deeper depths. However, at the same depth, the concentration value in different cycles varies little, due to the fast water penetration process at early stages.

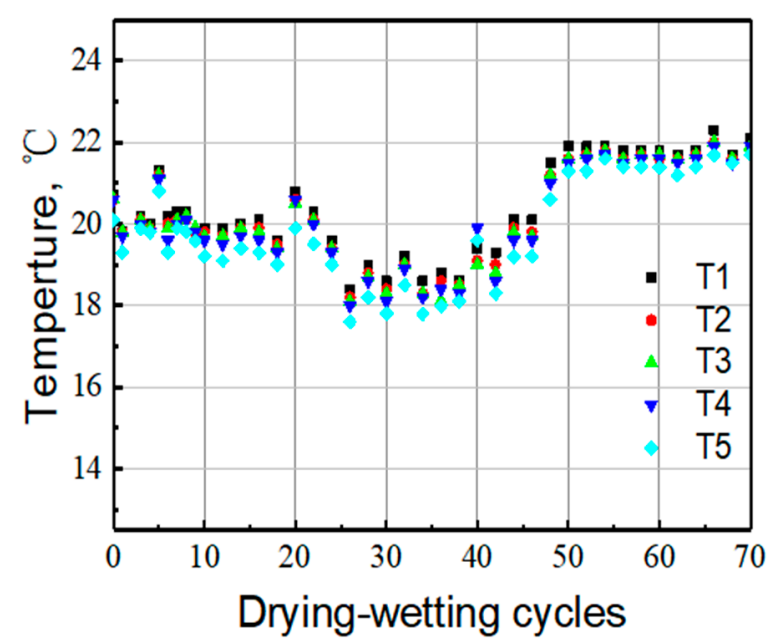

Figure 7. Temperature evolution with the development of dry-wet cycles by the humidity sensor in mortar sample.

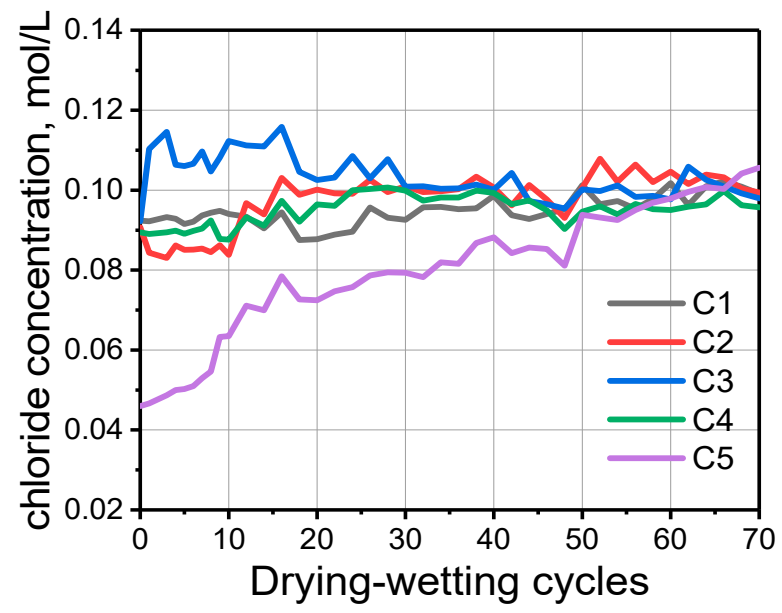

Figure 8. Chloride concentration calculated by Nernst's law with presence of temperature correction.

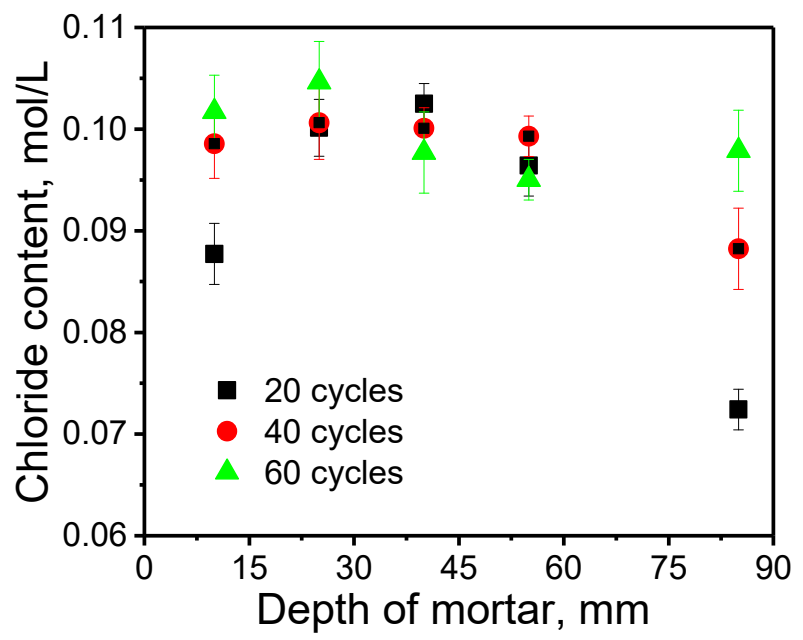

Figure 9. The chloride distribution at 20,40, 60 cycles. 


\subsection{Error Source in Potentiometry of Solution and Mortar}

The chloride ion sensor has high sensitivity and selectivity to chloride ion concentration. However, results are influenced and restricted by many factors, e.g., interfering ion, high $\mathrm{pH}$, temperature. In addition, the preparation method of $\mathrm{Ag} / \mathrm{AgCl}$ electrode and installation distance from the reference electrode will affect the final test results [19].

Considering above interfering factors, the potential response curve is linear in solution, but fluctuates markedly in mortar. In previous literature [28], the performance of the electrode is calibrated by adding $\mathrm{NaCl}$ solution into fresh mortar. Such curves are relatively flat as well. In this study, chloride ions are introduced into cement mortar through dry and wet circulation, which is more similar to actual engineering conditions. The results illustrate that dry-wet cycles have a great influence on the accuracy of electrode test results, but the variation rule of chloride ion can still be obtained through a large amount of data. The reason for this effect may be caused by the continuous variation of the internal stress and strain environment of mortar caused by the alternations of wet and dry or the change of ion concentration in the pore solution, which needs to be further studied.

It can be seen that the potential responses $\mathrm{Ag} / \mathrm{AgCl}$ electrodes are influenced by hydration throughout total service life in cement sample. It is characterized by violent potential fluctuations in the early hydration period and a continuous potential decline in dependence on adsorption of hydration products such as calcium silicate hydrate. It seems that the corresponding datum is meaningless in the early hydration period. Moreover, if accurate value is required, the effect of hydration and hydration products needs to be considered. Potential response of $\mathrm{Ag} / \mathrm{AgCl}$ electrodes for both absence or presence of $\mathrm{Cl}^{-}$interference in cement sample irregularly oscillates during total test procedure. This manifests that $\mathrm{Ag} / \mathrm{AgCl}$ sensors are of little value for quantitatively determining the free chloride concentration in mortar pore solution during dry-wet cycles, and it seems only able to indicate qualitative variation trends of chloride.

\subsection{A Comparison of ALS and Ag/AgCl Electrode in Mortar}

ALS used as corrosion sensor has been widely applied in various reinforced concrete structures. In marine environment, chloride is the main reason initiating corrosion potential change of anodes since once the chloride concentration in the spatial domain around the anodes reaches a threshold value, the anode will turn into active state, resulting in a significant change of voltage and current between the anode and cathode. When the metal holders are mounted to the embedded steel, six anodes, which are made of common carbon steel, have different distance from the sample surface. According to the depassivation signals, one by one during the penetration of the aggressive substance, the depassivation front can be traced, and the process of chloride penetration can be probably predicted. A simple comparison of $\mathrm{ALS}$ and $\mathrm{Ag} / \mathrm{AgCl}$ electrode in mortar is conducted to give some comprehensive understanding of performance of $\mathrm{Ag} / \mathrm{AgCl}$ electrode under dry-wet cycle condition.

Potential evolution of each anode with the development of dry-wet cycles in mortar sample can be observed from Figure 10. That all potential values are totally negative illustrates that the anode potential is less than the cathode potential and anodic steel reinforcement prone to lose electrons, leading to the depassivation of the steel surface. The corrosion risk can be assessed by corrosion potential according to corrosion standard for reinforcement in China, which is also dispalyed in Figure 10. It can be deduced that except A1, the corrosion risk of all steel is less than 10\%. A1 initiates corrosion at the 51 cycles and reaches potential equilibrium at 60 cycles. Current evolution with the development of dry-wet cycle of ALS in mortar sample is shown in Figure 11 and in such a manner that the corrosion current is defined as the positive current. The negative current represents the corrosion current of the reinforcement, indicating that the reinforcement embedded in the mortar is prone to corrosion. The variation tendency of current accords well with potential curve. At the initial phase, curve oscillates due to mortar interior environmental changes caused by cement hydration. This negative current indicates that the electron is moving towards the cathode, and the anode is 
prone to be corroded. From Figure 11, it can be seen that there is a significant increase of the negative corrosion current density of A1 after 50 cycles.

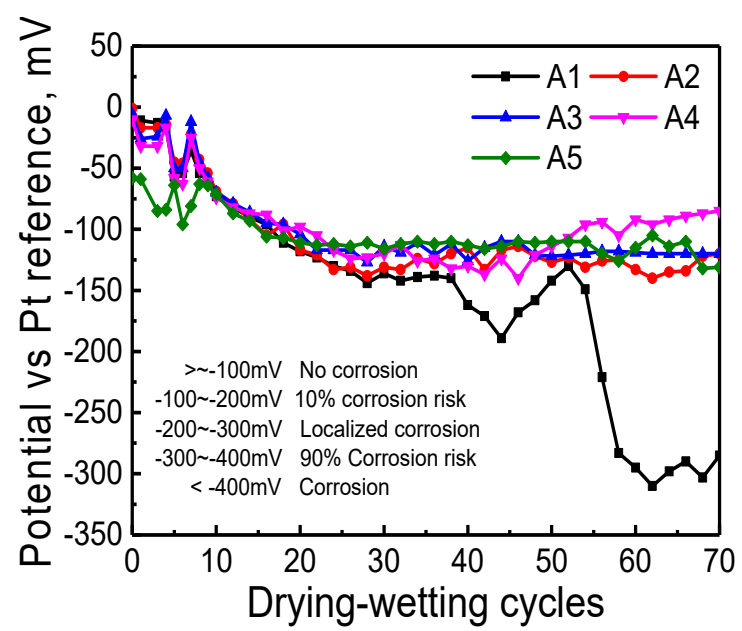

Figure 10. Potential (against Pt reference) evolution with the development of dry-wet cycles of ALS in mortar sample.

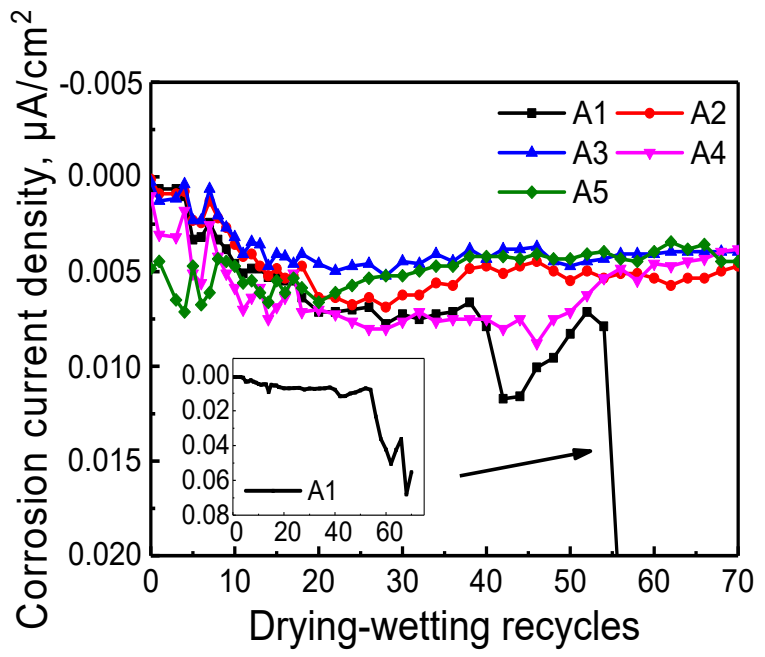

Figure 11. Current evolution with the development of dry-wet cycles of ALS in mortar sample.

Although ALS has been widely used in various projects, it has many unconquerable limits. For example, the results from ALS just displayed the corrosion behavior of adopted material, not the steel used in cement-based material, resulting in a certain difference. In some cases requiring accurate prediction or monitoring, this error is unneglectable.

It can be seen that both ALS and $\mathrm{Ag} / \mathrm{AgCl}$ electrode have an unstable period in the early stage. Then the curves of both the potential and the current became relatively flat until the cycles reach about 50 cycles. After around 50 cycles, the corrosion potential and the current of A1 increase significantly. The sudden shift of potential indicated that the chloride concentration on the surface of steel has reached a critical value leading to depassivation of the passivation film. Because the corrosion signal of ALS is the corrosion potential of the steel bar depassivation, the concentration of chloride ion has reached the critical value of depassivation, which illustrates that ALS has a certain hysteresis about chloride concentration change when compared to $\mathrm{Ag} / \mathrm{AgCl}$ electrode. The potential of $\mathrm{Ag} / \mathrm{AgCl}$ electrode is affected by the chloride ions in the solution. In comparison, for the ALS, the potential will only change if the concentration of chloride ions around it reaches a certain value, while the corrosion potential can only be obtained by anode ladder. In theory, the critical chloride content can be obtained 
by the combination of ALS and silver chloride electrode. However, it seems that the obtained critical chloride content has a certain error because of the interference from dry-wet cycle.

\section{Conclusions}

In the present work, $\mathrm{Ag} / \mathrm{AgCl}$ electrodes were prepared using continuous current and were calibrated in synthetic pore solution. The performance of $\mathrm{Ag} / \mathrm{AgCl}$ electrodes in reinforcement corrosion monitoring is evaluated in mortar. The main conclusions are summarized as follows:

The dry-wet cycle greatly promotes the permeability and transmission of water and chloride ions to the cement mortar. During the process of chloride, ions penetrate into the cement-based materials; in situ monitoring by mean of $\mathrm{Ag} / \mathrm{AgCl}$ electrode to some extent can reflect chloride content under dry-wet cycle condition. However, the dispersion of testing results is significantly affected by the dry-wet cycles. In addition, temperature correction is necessary for obtaining a more precise potential value. Finally, in terms of detecting the chloride ions, the $\mathrm{Ag} / \mathrm{AgCl}$ is more sensitive than the ALS.

Author Contributions: Conceptualization, P.Z. and T.Z.; Formal Analysis, P.Z. and T.Z.; Investigation, Y.T.; Resources, P.Z. and T.Z.; Writing-Original Draft Preparation, Y.T., K.Z. and Z.D.; Writing-Review \& Editing, Y.T.; Supervision, P.Z. All authors have read and agreed to the published version of the manuscript.

Funding: National Natural Science Foundation of China, grant number 51922052, 51778309, U1706222; Natural Science Foundation of Shandong Province, grant number ZR2018JL018; Open Research Fund Program of State Key Laboratory of Hydroscience and Engineering, grant number SKLHSE-2019-C-04.

Conflicts of Interest: The authors declare no conflict of interest.

\section{References}

1. Duffó, S.; Farina, S.B. Development of an embeddable sensor to monitor the corrosion process of new and existing reinforced concrete structures. Constr. Build. Mater. 2009, 23, 2746-2751. [CrossRef]

2. Zhang, P.; Wittmann, F.H.; Vogel, M.; Müller, H.S.; Zhao, T. Influence of freeze-thaw cycles on capillary absorption and chloride penetration into concrete. Cem. Concr. Res. 2017, 100, 60-67. [CrossRef]

3. Zhang, X.; Yang, S.; Zhang, W.; Guo, H.; He, X. Influence of outer rust layers on corrosion of carbon steel and weathering steel during wet-dry cycles. Corros. Sci. 2014, 82, 165-172. [CrossRef]

4. Legat, A. Monitoring of steel corrosion in concrete by electrode arrays and electrical resistance probes. Electrochim. Acta 2007, 52, 7590-7598. [CrossRef]

5. Zhang, P.; Wittmann, F.H.; Zhao, T.; Lehmann, E.H. Neutron imaging of water penetration into cracked steel reinforced concrete. Phys. B: Condens. Matter 2010, 405, 1866-1871. [CrossRef]

6. Wang, Y.R.; Cao, Y.B.; Zhang, P.; Ma, Y.W.; Zhao, T.J.; Wang, H.; Zhang, Z.H. Water absorption and chloride diffusivity of concrete under the coupling effect of uniaxial compressive load and freeze-thaw cycles. Constr. Build. Mater. 2019, 209, 566-576. [CrossRef]

7. Abbas, Y.; Have, B.t.; Hoekstra, G.I.; Douma, A. Connecting to Concrete: Wireless Monitoring of Chloride ions in Concrete structures. Procedia Eng. 2015, 120,965-968. [CrossRef]

8. Roy, R.N.; Vernon, W.; Bothwell, A.L.M. Standard potentials of the silver/silver chloride electrode from 5 to $45^{\circ} \mathrm{C}$ and the thermodynamic properties of hydrochloric acid in 95 mass per cent isopropanol. J. Chem. Thermodyn. 1971, 3, 769-777. [CrossRef]

9. Elsener, B.; Zimmermann, L.; Böhni, H. Non destructive determination of the free chloride content in cement-based materials. Mater. Corros. 2015, 54, 440-446. [CrossRef]

10. Martínez, C. Andrade, Examples of reinforcement corrosion monitoring by embedded sensors in concrete structures. Cem. Concr. Compos. 2009, 31, 545-554. [CrossRef]

11. Gao, X.J.; Zhang, J.; Yang, Y.Z.; Lu, S. Preparation of Chloride Ion Selective Electrode and its Potential Response to Different Chloride Solutions Representing Concrete Environments. Mater. Sci. Forum 2011, 675, 537-540. [CrossRef]

12. Yun, M.H.; Yeon, J.W.; Hwang, J.; Hong, C.S.; Song, K. A calibration technique for an Ag/AgCl reference electrode utilizing the relationship between the electrical conductivity and the $\mathrm{KCl}$ concentration of the internal electrolyte. J. Appl. Electrochem. 2009, 39, 2587-2592. [CrossRef] 
13. Suzuki, H.; Hirakawa, T.; Sasaki, S.; Karube, I. An integrated three-electrode system with a micromachined liquid-junction Ag/AgCl reference electrode. Anal. Chim. Acta 1999, 387, 103-112. [CrossRef]

14. Qiao, G.; Xiao, H.; Yi, H.; Qiu, Y. Preparation and characterization of the solid-state Ag/AgCl reference electrode for RC structures. Sens. Rev. 2013, 32, 118-122. [CrossRef]

15. Brewer, P.J.; Leese, R.J.; Brown, R.J.C. An improved approach for fabricating Ag/AgCl reference electrodes. Electrochim. Acta 2012, 71, 252-257. [CrossRef]

16. Chen, X.; Zhiyuan, L.; Weiliang, J. A new corrosion sensor to determine the start and development of embedded rebar corrosion process at coastal concrete. Sensors 2013, 13, 13258-13275.

17. Pargar, F.; Koleva, D.A.; Van Breugel, K. Determination of Chloride Content in Cementitious Materials: From Fundamental Aspects to Application of Ag/AgCl Chloride Sensors. Sensors 2017, 17, 2482. [CrossRef]

18. Takashi, K.; Takahiro, Y.; Naoya, N. New class of Ag/AgCl electrodes based on hydrophobic ionic liquid saturated with AgCl. Anal. Chem. 2007, 79, 7187-7191.

19. Stoica, D.; Brewer, P.J.; Brown, R.J.C.; Fisicaro, P. Influence of fabrication procedure on the electrochemical performance of Ag/AgCl reference electrodes. Electrochim. Acta 2011, 56, 10009-10015. [CrossRef]

20. Gao, P.; Jin, X.; Wang, D.; Hu, X.; Chen, G.Z. A quartz sealed Ag/AgCl reference electrode for $\mathrm{CaCl}_{2}$ based molten salts. J. Electroanal. Chem. 2005, 579, 321-328. [CrossRef]

21. Prkić, A.; Vukušić, T.; Mitar, I. New sensor based on AgCl containing Iron Oxide or Zinc Oxide Nanoparticles for Chloride Determination. Int. J. Electrochem. Sci. 2019, 14, 861-874. [CrossRef]

22. Kim, T.Y.; Hong, S.A.; Yang, S. A solid-state thin-film Ag/AgCl reference electrode coated with graphene oxide and its use in a pH sensor. Sensors 2015, 15, 6469-6482. [CrossRef] [PubMed]

23. Jin, M.; Xu, J.; Jiang, L.; Xu, Y.; Chu, H. Investigation on the performance characteristics of chloride selective electrode in concrete. Ionics 2015, 21, 2981-2992. [CrossRef]

24. Climent-Llorca, M.A.; Viqueira-Pérez, E.; Ma, L.A. Embeddable Ag/AgCl sensors for in-situ monitoring chloride contents in concrete. Cem. Concr. Res. 1996, 26, 1157-1161. [CrossRef]

25. Atkins, C.P.; Scantlebury, J.D.; Nedwell, P.J. Monitoring chloride concentrations in hardened cement pastes using ion selective electrodes. Cem. Concr. Res. 1996, 26, 319-324. [CrossRef]

26. Nilsson, L.O.; Ollivier, J.P. Chloride penetration non-destructive determination of the free chloride content in mortar and concrete. In RILEM International Workshop on Chloride Penetration into Concrete; RILEM Publications SARL: Bagneux, France, 1995; pp. 17-26.

27. Moreno, M. Zerstörungsfreie Erfassung der gelösten Chloride im Beton. PhD Thesis, ETH Zurich, Zurich, Switzerland, 1993.

28. Hidalgo, A.; de Vera, G.; Climent, M.A. Measurements of chloride activity coefficients in real Portland cement paste pore solutions. J. Am. Ceram. Soc. 2001, 84, 3008-3012. [CrossRef]

29. Angst, U.; Elsener, B.; Larsen, C.K.; Vennesland, Ø. Potentiometric determination of the chloride ion activity in cement-based materials. J. Appl. Electrochem. 2009, 40, 561-573. [CrossRef]

30. Du, G.R.; Hu, G.R.; Huang, S.R. In situ measurement of $\mathrm{Cl}$-concentrations and $\mathrm{pH}$ at the reinforcing steel/concrete interface by combination sensors. Anal. Chem. 2006, 78, 3179-3185. [CrossRef]

31. Pargar, F.; Kolev, H.; Koleva, A.D. Microstructure, surface chemistry and electrochemical response of $\mathrm{Ag} / \mathrm{AgCl}$ sensors in alkaline media. J. Mater. Sci. 2018, 53, 7527-7550. [CrossRef]

32. Montemor, M.F.; Alves, J.H.; Simoes, A.M.; Fernandes, J.C.S. Multiprobe chloride sensor for in situ monitoring of reinforced concrete structures. Cem. Concr. Compos. 2006, 28, 233-236. [CrossRef]

33. Jin, M.; Jiang, L.; Zhu, Q. Monitoring chloride ion penetration in concrete with different mineral admixtures based on embedded chloride ion selective electrodes. Constr. Build. Mater. 2017, 143, 1-15. [CrossRef]

34. Zhang, P.; Hou, D.S.; Liu, Q.; Liu, Z.L.; Yu, J. Water and chloride ions migration in porous cementitious materials: An experimental and molecular dynamics investigation. Cem. Concr. Res. 2017, 102, 161-174. [CrossRef]

35. Shang, H.S.; Ren, G.S.; Hou, D.S.; Zhang, P.; Zhao, T.J. Bond behaviour between steel bar and concrete under sustained load and dry-wet cycles. Mag. Concr. Res. 2019, 71, 700-709. [CrossRef]

36. Bao, J.W.; Li, S.G.; Zhang, P.; Ding, X.Y.; Xue, S.B.; Cui, Y.F.; Zhao, T.J. Influence of the incorporation of recycled coarse aggregate on water absorption and chloride penetration into concrete. Constr. Build. Mater. 2020, 239, 117845. [CrossRef]

37. Gang, X.; pan, L.Y.; biao, S.Y.; Ke, X. Chloride ion transport mechanism in concrete due to wetting and drying cycles. Struct. Concr. 2015, 16, 289-296. [CrossRef] 
38. Cao, C. Preparation and Characterization of AgCl-MnO ${ }_{2}$ Chloride Sensor. Master' Thesis, Qingdao University of Technology, Qingdao, China, 2016.

39. Muralidharan, S.; Ha, H.T.; Bae, H.J. Electrochemical studies on the solid embeddable reference sensors for corrosion monitoring in concrete structure. Mater. Lett. 2006, 60, 651-655. [CrossRef]

40. Vera, D.G.; Climent, M.A.; Antón, C. Determination of the selectivity coefficient of a chloride ion selective electrode in alkaline media simulating the cement paste pore solution. J. Electroanal. Chem. 2010, 639, $43-49$. [CrossRef]

41. Biedermann, G.; Sillén, G.L. Studies on the hydrolysis of metal ions. 30. A critical survey of the solubility equilibria of $\mathrm{Ag}_{2}$ O. Acta Chim. Sin. 1960, 14, 717-725. [CrossRef]

(C) 2020 by the authors. Licensee MDPI, Basel, Switzerland. This article is an open access article distributed under the terms and conditions of the Creative Commons Attribution (CC BY) license (http://creativecommons.org/licenses/by/4.0/). 